
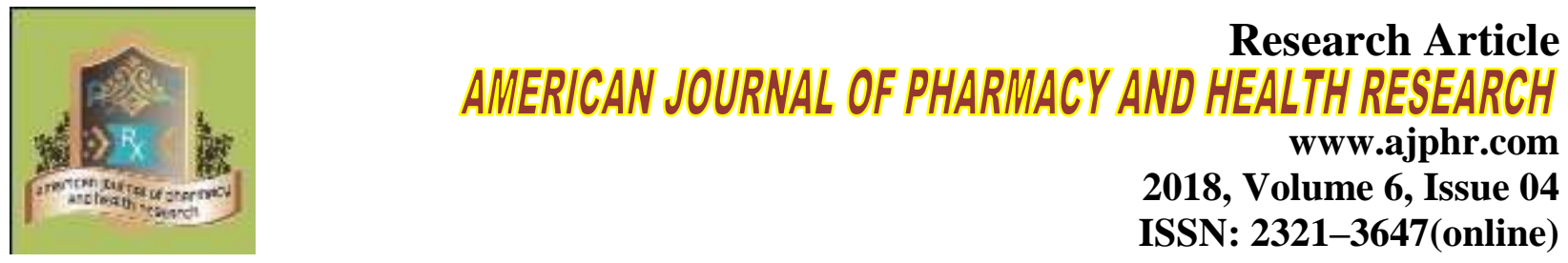

2018, Volume 6, Issue 04

ISSN: 2321-3647(online)

\title{
Effect of Altitude (2500 M) on The Pharmacokinetics of Diclofenac Sodium and Cefadroxil After Oral Administration To Human Volunteers
}

\author{
Fergany.A. Mohammed ${ }^{1 *}$, Mostafa.A. Hussein ${ }^{2}$ \\ 1.College of Clinical Pharmacy, Albaha University, Albaha, P.O. Box (1598) Kingdom of Saudi \\ Arabia (KSA) \\ 2. Faculty of Pharmacy, Assiut University, Assiut-Egypt.
}

\section{ABSTRACT}

This paper reports, for the first time, the data on the pharmacokinetic characteristics of diclofenac sodium and cefadroxil at Albaha, 2500 M altitude (ALT), KSA. Therefore, the objective of this study was to compare the plasma concentrations and pharmacokinetic parameters of diclofenac sodium (Voltaren ${ }^{\circledR} 50$ tablets, Ciba Geigy, USA) and cefadroxil (Ultrcef $^{\circledR} 500$ capsules, Bristol L. Germany) at altitude of $2500 \mathrm{M}$ (ALT) and at sea level (SEA) after oral administration to 12 healthy volunteers. A two-way cross over study design was used to compare pharmacokinetic parameters at ALT and SEA. Following drug administration, blood withdrawn into heparinized test tubes over a period of 12 hours. Drug concentrations were determined in the withdrawn samples by fully validated and optimized HPLC methods for the two drugs. The pharmacokinetic parameters including $\mathrm{C}_{\max }, \mathrm{t}_{\max }, \mathrm{t}_{0.5 \mathrm{e}}, \mathrm{t}_{0.5 \mathrm{a}}, \mathrm{K}_{\mathrm{e}}, \mathrm{K}_{\mathrm{a}}, \mathrm{V}_{\mathrm{d}}$, $\mathrm{Cl}_{\mathrm{T}}, \mathrm{AUC}_{0-12 \mathrm{~h}}$, and $\mathrm{AUC}_{0-\infty}$ were determined by a computer programs. Statistical analysis of the obtained plasma drug concentrations and pharmacokinetic parameters were performed using ANOVA computerized system. Results obtained showed significant differences in the plasma concentrations and all pharmacokinetic parameters of the two drugs at ALT as compared to SEA. There was a significant increase in $\mathrm{C}_{\max }$ and $\mathrm{AUC}_{0-12 \mathrm{~h}}$, of both drugs at ALT as compared to SEA. The values of $\mathrm{Vd}$ and $\mathrm{Cl}_{\mathrm{T}}$ were significantly lower at ALT than SEA. ALT could markedly inhibit the metabolism and renal excretion of both drugs as indicated by significant increase in the elimination half-lives $\left(\mathrm{t}_{0.5 \mathrm{e}}\right)$ and decrease in the elimination rate constant $\left(\mathrm{K}_{\mathrm{e}}\right)$ at ALT as compared to SEA. The obtained results clearly indicate that the plasma concentrations and all the pharmacokinetic parameters of both diclofenac sodium and cefadroxil are significantly modified by ALT. Therefore, dosage regiemens adjustment is important when diclofenac sodium and cefadroxil are prescribed for administration at ALT to maintain drug efficacy and safety and to avoid drug's toxicity.

Keywords: altitude- ALT- SEA- diclofenac sodium- cefadroxil- fully validated HPLC- drug concentrations- pharmacokinetic parameters- statistical analysis - significant differences- dosage regimen adjustment -avoid drug's toxicity 


\section{INTRODUCTION}

High-altitude environments are known to result in a broad range of physiological changes in human body, which may influence various pharmacological processes and pharmacokinetics. A series of physiological systems reacting to a high-altitude stressor and the effects of these physiological alterations on pharmacokinetics have been investigated for decades [1-33]. The effects of high altitude on human physiological alterations (including those in the gastrointestinal system, cardiovascular system, pulmonary system, hematocrit, drug metabolism enzyme system, and renal excretory system), as well as subsequent changes of pharmacokinetics (such as absorption, distribution, metabolism, and excretion of drugs)(ADME) [1-9]. High altitudes can lead to a broad range of physiological changes, leading to the changes in the ADME process of drugs [10-20]. According to previous pharmacokinetics studies in human, the pharmacokinetics changes due to high altitude exposure may require dosage regimen modifications to maintain drug efficacy and safety, which should draw our attention to drug administration dosage for those planning ascent to high altitudes [1-3,21-33]. Previous studies have demonstrated hypoxia at high altitude can adversely affect both drug metabolism and toxicity [21-33].

Hypoxia, a subnormal oxygen concentration in cells is an important consideration in pharmacology because (i) altered cellular function may affect the therapeutic effectiveness of an agent, (ii) therapeutic agents may potentiate or protect against hypoxic pathology, (iii) hypoxia may increase or decrease drug-induced toxicity, and (iv) may alter the rate of drug metabolism and thus the effective therapeutic dose. The liver is the most important site for systemic drug metabolism. Phase I (oxidation, reduction and hydrolysis) and phase II (conjugation) reactions convert lipophilic drugs into more polar and hence more readily excreted metabolites. The rate of metabolism of lipophilic drugs is the most important factor affecting the intensity and duration of their action [10-15].

The role of hypoxia in modulating drug metabolism has been largely investigated in vitro and in animal studies. A few studies conducted in men exposed to high altitude hypoxia are inconclusive. In one study [14 ] healthy subjects who lived at sea level were exposed to altitude induced hypoxia for 7 days at $4559 \mathrm{~m}$ above sea level. Hepatic CYP enzyme activity was measured before departure, at 24 and $96 \mathrm{~h}$ after arrival to high altitude location and at 1 month after return to sea level. No clinically significant effect of acute hypoxia on CYP enzymes was observed [10-14,19]. In another study in human patients of chronic hypoxemia $(\mathrm{PaO} 2<55$ 
$\mathrm{mmHg}$ ), antipyrine half-life was increased by 20 per cent indicating slower biotransformation of the drug [10-14,19].

An open-label, controlled, prospective study was conducted to investigate the pharmacokinetics of sulphamethoxazole in healthy Chinese male volunteers at low and high altitudes ${ }^{23}$. Significant changes were reported in the disposition of sulphamethoxazole in these subjects after either acute or chronic exposure to an altitude of $\sim 3780 \mathrm{~m}$ in comparison to those residing at an altitude of 400 $\mathrm{m}[23]$.

It has been reported that no substantial change occurs in cytochrome P450 and b5 in mice subjected to acute hypoxia [4,24]. Oxygen-requiring processes of hepatic heme and drug metabolism remain well maintained during hypoxia [25]. A decrease in hepatic cytochrome P450 content in rats submitted to $5,500 \mathrm{~m}$ simulated altitude for 35 days has been reported but no change in rats subjected to $4400 \mathrm{~m}$ for 6 to 8 months was observed [4,22,24].

The influence of moderate hypoxia or hypercapnia on salbutamol kinetics and its hypokaliaemic effect, following its administration through the intravenous, intra-tracheal, and oral routes was studied [22], concluding that salbutamol kinetics and dynamics can be altered by hypoxia and hypercapnia. Thallium kinetics was studied during normoxia and hypoxia in cultured chick ventricular cells ${ }^{23}$. The results showed that cellular accumulation of thallium and the rate of washout of thallium were minimally decreased by hypoxia independent of blood flow. The effect of hypoxia and hyperoxia on the pharmacokinetics of protocol emulsion, hepatic blood flow and arterial ketone body ratio in the rabbit has been studied [27], indicating that hypoxia produced an accumulation of propofol in blood and reduced its clearance which could be due to decreased hepatic blood flow and low energy change in the liver. The effect of hypobaric hypoxia on several commonly used drugs in rats and rabbits exposed to chronic intermittent hypoxia [25,27]. Pentobarbital is a short acting barbiturate approved as a short-term hypnotic and veterinary use as an anesthetic [25]. Therefore, sleeping time test was used for preliminary investigations on whether hypoxic stress interferes with metabolism of drugs. Significantly prolonged sleeping time with pentobarbitone and thiopentone sodium in hypoxia-exposed rats suggests slowed elimination of these drugs. Similar results have been reported earlier in rabbits [24,25]. Also reduced rate of pentobarbital disappearance in mice during exposure to acute hypoxia suggesting depressed in vivo metabolism of pentobarbital and enhanced CNS sensitivity to the barbiturates have been reported [17,25-27]. Significantly prolonged sleeping time with pentobarbitone and thiopentone sodium in hypoxia-exposed rats suggests slowed elimination of these drugs. Similar results have been reported earlier in rabbits [22]. Also reduced rate of pentobarbital 
disappearance in mice during exposure to acute hypoxia suggesting depressed in vivo metabolism of pentobarbital and enhanced CNS sensitivity to the barbiturates have been reported [25]. Pharmacokinetics of some of the commonly used drugs has been investigated. Acetyl salicylic acid has been reported to have neuroprotective action against hypoxic hypoxia and chemical hypoxia [28]. Acetazolamide is a carbonic anhydrase inhibitor and is the mainstay for prevention and treatment of acute mountain sickness [29]. Gentamicin is an aminoglycoside antibiotic, used to treat many types of bacterial infections, particularly those caused by Gramnegative bacteria, and phenobarbitone is used for treatment of epileptic seizures. Elimination of aminoglycosides after parenteral administration occurs almost entirely by glomerular filtration [30-31]. A delay in half-life of gentamicin as well as acetazolamide has been reported. Both the drugs do not require any metabolic transformation before elimination by kidneys. The elimination half-life for gentamicin has been reported to be $1 \mathrm{~h}$ in rabbits which is quite similar to the values found in control rabbits in the present study. Elimination rates can be highly variable with the aminoglycoside antibiotics in humans with normal renal function. Patients with decreased renal function can have significantly prolonged half-lives for gentamicin clearance [30-31]. A significant increase in the pharmacokinetics of drugs like aminoglycosides eliminated through the kidneys may be impaired and require a different than usual dosage regimen under various physiological, pathological and environmental conditions [30-31]. A decrease in body temperature is associated with a decrease in glomerular filtration rate in rats ${ }^{31}$, in other species and in humans are temperature requiring processes and hence temperature sensitive $\mathrm{e}^{32}$ and may, therefore, impair the elimination of aminoglycosides. Hypoxia altered renal function and gentamicin pharmacokinetics [25-31-31]. Therefore, altered renal function during hypoxia could be the reason for prolonged stay of these drugs in plasma [32,33].

Diclofenac sodium or sodium [O-(2,6-dichlorophenyl)-amino-phenyl]acetate is a non-steroidal antiinflammatory analgesic with potent cycloxygenase inhibition activity [43-36]. This drug is commonly used in the treatment of post-operative pain, rheumatoid arthritis and chronic pain associated with cancer [37]. Diclofenac is well absorbed after oral administration with extensive hepatic metabolism [37]. The extensive first pass metabolism, combined with low enterohepatic circulation reduces oral bioavailability of diclofenac in humans to 50 - $60 \%$ of the administered dose. This compound exhibits a terminal half life of 1-2 h, volume of distribution of $0.171 / \mathrm{kg}$, $99 \%$ protein binding and enters the synovial fluid [37]. The drug is well absorbed orally and dissolves in the intestinal fluid. Food has no significant effect on the extent of diclofenac absorption but can cause a delay in the onset of absorption and a reduction in peak plasma levels 
of approximately 30\%. [38-40]. There are large number of studies on determination of diclofenac sodium [40-56].

Cefadroxil is a semi-synthetic first generation oral cephalosporin, similar to cephalexin and cephradine in structure and spectrum of antibacterial activity. It is used in the treatment of mild to moderate infections of the respiratory and urinary tracts, skin and soft tissue infections [5759]. Furthermore it has been used in the prophylaxis of recurrent urinary tract infections in children [59]. Although the microbiological activities of cephalosporins are similar when measured by traditional susceptibility testing systems, a study using a kinetic model to simulate the blood concentrations in man showed cefadroxil to be more active than cephalexin and cephradine against Staphylococcus aureus, Streptococcus pneumoniae, and Streptococcus pyogenes. This suggests that the more sustained serum and tissue concentrations of cefadroxil improve its microbiological activity in the blood stream[59]. Cefadroxil is acid-stable and has a phenyl-glicine side chain that is responsible for almost completely oral absorption. The rate of absorption and serum peak concentration of cefadroxil were not affected when the drug is administered with food and over $90 \%$ of the drug is excreted unchanged in urine within $24 \mathrm{~h}$ [59]. The peak serum concentrations are achieved within 1.5-2.0 h and average about 10-18 $\mu \mathrm{g} / \mathrm{mL}$ following a single oral administration 500mg dose. The plasma half-life elimination of cefadroxil is 1.1-2.0 hr in adults with normal renal function. Cefadroxil produces higher concentrations in body tissues and fluids, such as sputum, lung, pleura, and skin blisters than cephalexin and cephradine. A dose of 500mg cefadroxil is sufficient to treat different infections. Cefadroxil is generally well tolerated and adverse effects do not appear to be a serious problem. There are large number of studies for determination of cefadroxil [57,60,61].

\section{Aim of study}

The protocol of this study aimed to investigate and evaluate the effects of low atmospheric pressure and oxygen deficiency in breathing in Albaha area $2500 \mathrm{M}$ above sea level (ALT), Kingdom of saudi Arabia (KSA) on the blood concentrations and pharmacokinetic parameters two of the most widely utilized drugs, diclofenac sodium (Voltaren ${ }^{\circledR} 50 \mathrm{mg}$ tablets oral tablets) and cefadroxil (ULTRACEF ${ }^{\circledR} 500$ oral capsules), after administration to 12 healthy volunteers living for at least one month at Albaha (ALT) following one month at Al-mokhwah, sea level (SEA). A two-way single oral dose crossover study was conducted to compare the blood concentrations and pharmacokinetic parameters of the two drugs. Following drug administration, blood samples $(10 \mathrm{ml})$ were withdrawn into heparinized test tubes at zero time (before 
administration, blank) and at $0.5,1,2,2,4,8,10$ and 12 hours after administration. Drug concentrations in the plasma samples was determined by fully validated and optimized HPLC methods for diclofenac sodium and cefadroxil. The pharmacokinetic parameters including $\mathrm{C}_{\max }$, $\mathrm{t}_{\max }, \mathrm{t}_{0.5}, \mathrm{~K}_{\mathrm{e}}, \mathrm{V}_{\mathrm{d}}, \mathrm{Cl}_{\mathrm{t}}, \mathrm{AUC}_{0-\mathrm{t}}$, AUC $0-10 \mathrm{~h}$, and $\mathrm{AUC}_{0-\infty}$ was determined by computerized programs. Statistical analysis of the obtained pharmacokinetic parameters was performed using ANOVA computerized system.

\section{MATERIALS AND METHOD}

\section{Chemicals and reagents}

Diclofenac sodium, mephenamic acid, cefadroxil and amoxicillin were kindly supplied by the United Pharmaceutical Company, Amman, Jordan. All organic solvents were of HPLC grade and were purchased from Lab-Scan-(United Kingdom). All reagents were of analytical grade and were purchased from GCC (United Kingdom). The deionized water was prepared using Milli-Q system (Millipore, Molsheim, France).

Commercial formulation Voltaren ${ }^{\circledR} 50$ tablets commercially marketed tablets containing 50 mg of diclofenac sodium, Produced by Ciba Geigy, Germany).

ULTRACEF $^{\circledR} 500$ Capsules (Commercially Marketed Capsules containing $500 \mathrm{mg}$ of Cefadroxil, Produced by Bristol Laboratories, USA) were purchased from local drugstore.

\section{Apparatus and chromatographic system}

The HPLC apparatus was composed of a computerized Hitachi system: a Hitachi pump (Model L-6200A), operated at a flow rate of $1.5 \mathrm{ml} / \mathrm{min}$, a variable UV detector (L-400A) set at $228 \mathrm{~nm}$, an interface (D-6000A) and a 100 $\mu$ l fixed volume autosampler (AS-2000). Separation was achieved on a stainless steel reversed-phase Lichrosphere C18 (25 x 4 mm, $5 \mu \mathrm{m}$ ) column (Life Sci. Int., London, England 330974) with a $\mathrm{C}_{18}$ pre-column (30 to $40 \mu \mathrm{m}$ ). The mobile phase consisted of a mixture of phosphate buffer ( $\mathrm{pH} 3)$ and acetonitrile at a ratio of (92:8 v/v).was filtered through a $0.45 \mu \mathrm{m}$ membrane filter and degassed using an ultrasonicator (Linda Sonic, Model LDS6, milano, Italia). The samples were centrifuged using Labofuge 200 (Heraeus, Model 3630, Germany). Vortex was achieved by an auto-vortex mixer (Stuart Scientific, SA2, UK). Chromatograms were recorded on a strip chart recorder (Epson LQ-1050) at a speed of $2.5 \mathrm{~mm} / \mathrm{min}$.

\section{Facilities}


The Clinical part of this study are performed in the medical center at Albaha University (Kingdom of Saudi Arabia, KSA) (low oxygen) (ALT) and Almoghwa medical center KSA where areas on normal pressure levels (SEA).

Drug analysis: are performed by using validated HPLC procedures.

\section{Selection of Volunteers}

Twelve healthy males volunteers $(24 \pm 2.7$ years of age, $165 \pm 4.5 \mathrm{~cm}$ height, and $75 \pm 4.6 \mathrm{~kg}$ weight) were studied at (SEA) and following one month of continuous exposure to altitude of $2500 \mathrm{M}$ at (ALT).

\section{Characterization:}

Selection criteria and exclusion criteria are reported previous studies [47, 67,68].

\section{Institutional Review Committee:}

The ethical committee responsible for studies on human subjects at Albaha University, Kingdom of Saudi Arabia (KSA) considered the protocol and the informed consent in details.

\section{Written Informed Consent:}

Informed consent will be provided to each prospective volunteer prior to entry into the study. Informed given to each volunteer will include the detail of the study, risks associated with participation and information regarding the right of withdraw at any time from participation without jeopardy. Copies of the signed and dated consent forms are provided to sponsor and kept in file.

\section{Healthy status of the volunteers:}

The healthy status of the volunteers were confirmed by physical and medical examination by general physician at the medical center and by blood and urine analysis indicating freedom from any kidney, hepatic or heart disease.

\section{Fasting:}

All volunteers are fasted for at least $10 \mathrm{hrs}$ prior to drug administration and for $2 \mathrm{hrs}$ after administration.

\section{Dosing:}

Single oral dose of diclofenac sodium (Voltaren ${ }^{\circledR} 50 \mathrm{mg}$ tablets oral tablets) and cefadroxil (ULTRACEF ${ }^{\circledR} 500 \mathrm{mg}$ oral capsules).

\section{Drugs (OTC and prescription) :}

Two weeks before and during the study day, the volunteers are not be allowed to take any medications. Smoking and Xanthine containing beverage are prohibited during the study day. 


\section{Physician and Nurses:}

All blood samples were withdrawn by professional nurses and under supervision of a physician from the medical center of Albaha university and medical center elsewhere the clinical part is to be conducted.

\section{Drug administration to the volunteers:}

The study protocol provide a single oral dose, two- way crossover study in 12 healthy volunteers comparing the effect of altitude (2500 M) (ALT) on the blood concentration and pharmacokinetic parameters of diclofenac Sodium (Voltaren50 mg tablets) and cefadroxil ULTRACEF $^{\circledR} 500$ as compared to sea level (SEA).

\section{Study design for diclofenac sodium and cefadroxil:}

The study design for both drugs is a single-dose, two-way crossover with one month washout period between the two phases of the study to Allow accommodation for ALT and SEA (table 1a and Table 1b).

Table 1a: Study design for diclofenac sodium

\begin{tabular}{lll}
\hline Phase & ALT* & SEA** \\
\hline Phase I & $1-6$ & $7-12$ \\
Phase II & $7-12$ & $1-6$ \\
Total Number of Volunteers & $\mathbf{1 2}$ & $\mathbf{1 2}$ \\
\hline
\end{tabular}

*ALT: Each volunteer receives one oral Voltaren ${ }^{\circledR} 50$ tablets at ALT.

**SE: Each volunteer receives one oral Voltaren ${ }^{\circledR} 50$ tablets at SEA.

Table 1b: Study design for cefadroxil

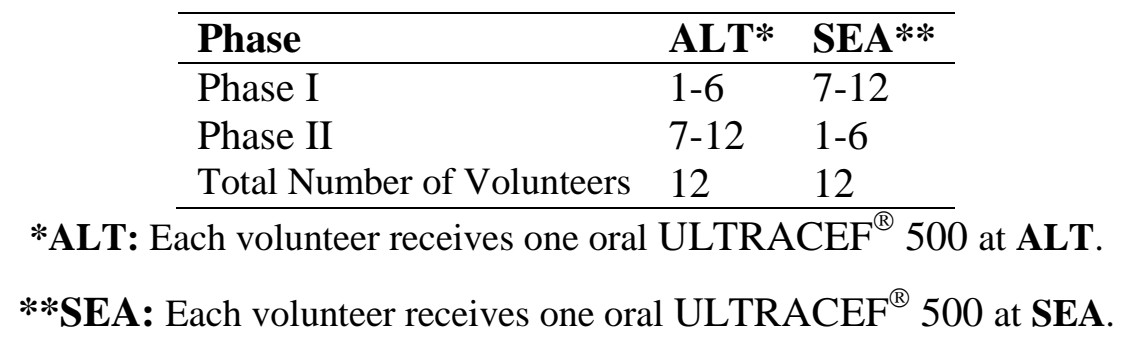

\section{Blood sampling:}

Blood samples $(10 \mathrm{ml})$ collection (over period of 12 hours) follows: pre-dose (0 hours) and at $0.5,1,2,3,4,8,10$, and $12 \mathrm{hrs}$ after drug administration. Plasma was separated immediately by centrifugation at $5000 \mathrm{rpm}$ and stored at $-20^{\circ} \mathrm{C}$ until analysis [65].

\section{Drug analysis for diclofenac sodium and cefadroxil in plasma}

Drug analysis was carried out by selective and sensitive methods of HPLC as described in the procedure for diclofenac sodium and cefadroxil. Assay validation included: Linearity, Sensitivity, Selectivity, Reproducibility, Accuracy and Precision. 


\section{Pharmacokinetic parameters:}

The following pharmacokinetic parameters of diclofenac sodium and cefadroxil were determined from the plasma concentration-time curves by using a non-compartmental model: $\mathrm{C}_{\max }, \mathrm{t}_{\max }, \mathrm{t}_{0.5 \mathrm{e}}$, $\mathrm{K}_{\mathrm{e}}, \mathrm{t}_{0.5 \mathrm{a}}, \mathrm{K}_{\mathrm{a}}, \mathrm{V}_{\mathrm{d}}, \mathrm{Cl}_{\mathrm{T}}, \mathrm{AUC}_{0-12}$ and $\mathrm{AUC}_{0-\infty} \cdot \mathrm{C}_{\max }$ (maximum plasmatic concentration), $\mathrm{t}_{\max }$ (time to $\mathrm{C}_{\max }$ ) were obtained directly from the concentration-time curve. $\mathrm{AUC}_{0-\mathrm{t}}$, area under the plasma concentration-time curve from zero to sample time of the last measurable concentration was calculated using the linear trapezoidal method. The elimination half-life $\left(t_{0.5}\right)$ was calculated from the terminal log-linear portion of the plasma; and the total body clearance $\left(\mathrm{Cl}_{\mathrm{T}}\right)$, apparent volume of distribution $\left(\mathrm{V}_{\mathrm{d}}\right)$, and elimination rate constant $\left(\mathrm{k}_{\mathrm{e}}\right)$ were calculated by the noncompartmental pharmacokinetic model. The absorption half-life $\left(\mathrm{t}_{0.5 \mathrm{a}}\right)$ and absorption rate constant $\left(\mathrm{k}_{\mathrm{a}}\right)$ were calculated by the method of residuals [63-65].

Statistical analysis was performed using an ANOVA for a repeated measures design with orthogonal contrasts to identify statistical differences between ALT and SEA for each plasma concentration and pharmacokinetic parameter. Statistical significant was set at $\mathbf{P}<\mathbf{0 . 0 5}[40,65]$.

\section{RESULTS AND DISCUSSION}

\section{Validation of analytical methods}

\section{Chromatographic selectivity and retention times}

\section{Diclofenac sodium}

Typical chromatograms of (a) blank human plasma, (b) blank human plasma spiked with the internal standard, MA (1 $\mu \mathrm{g} / \mathrm{ml})$, (c) blank plasma spiked with MA and DF $(2 \mu \mathrm{g} / \mathrm{ml}$ and (d) plasma taken $2 \mathrm{~h}$ after oral administration of Voltaren ${ }^{\circledR} 50$ tablets to a human volunteer are shown in figure 1. The selectivity of the method was demonstrated by the lack of interferences at the retention times of DF (3.4 min) and MA (4.8 min). Both peaks were sharp and symmetrical with good baseline resolution, thus facilitating accurate measurement of the peak height ratio (PHR). Potential interferences to the peaks were also evaluated by injecting some common drugs to the HPLC system. These drugs included Aspirin, Ketoprofen, Ibuprofen, naproxen, Amoxicillin and indomethacin. No one of these drugs exhibited the same retention times of DF (3.4 min) or MA (internal standard, IS) (4.8 min), indicating selectivity of the method (figure 1). 
PHR (DF/MA)

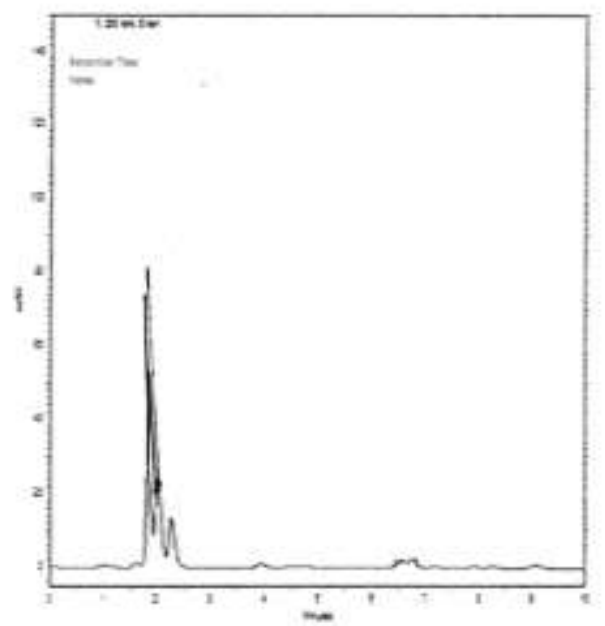

(a)

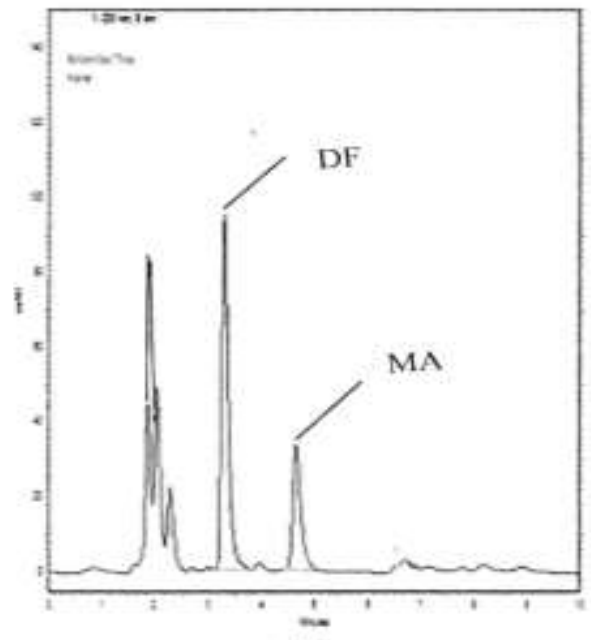

(c)

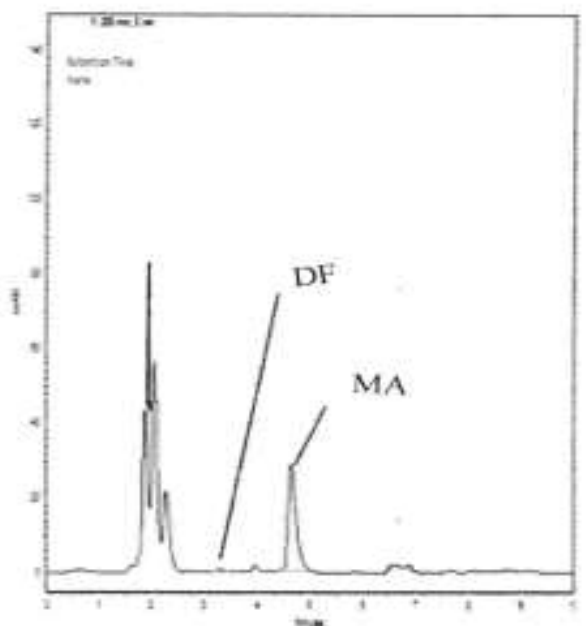

(b)

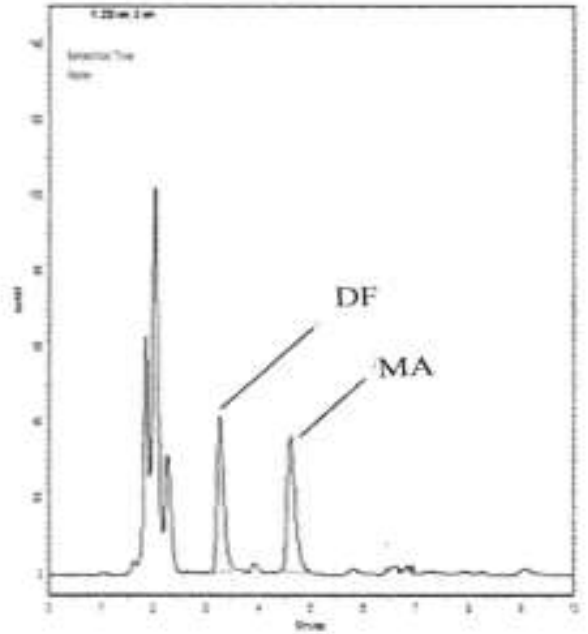

(d)

Retention time

Figure 1:Typical chromatograms of:

(a) Blank human plasma.

(b) Blank human plasma spiked with mephenamic acid $(1 \mu \mathrm{g} / \mathrm{ml})$

(c) BlankHuman plasma spiked with mephenamic acid (1 1 g/ml) and DF $(2 \mu \mathrm{g} / \mathrm{ml})$

(d) Human plasma taken 2 hours after oral administration of Voltaren $50^{\circ}$ tablets to a hum.

\section{Cefadroxil (Ultracef)}

Typical chromatograms of (a) blank human plasma spiked with the internal standard, Amoxicillin, AMO $(5 \mu \mathrm{g} / \mathrm{ml})$, (b) blank plasma spiked with AMO $(5 \mu \mathrm{g} / \mathrm{ml})$ and cefadroxil $(0.05$ $\mu \mathrm{g} / \mathrm{ml})$ and (c) blank plasma spiked with AMO (5 $\mu \mathrm{g} / \mathrm{ml})$ and CFL $(0.05 \mu \mathrm{g} / \mathrm{ml}$ and $4 \mu \mathrm{g} / \mathrm{ml})$ are shown in figure 2 a. 


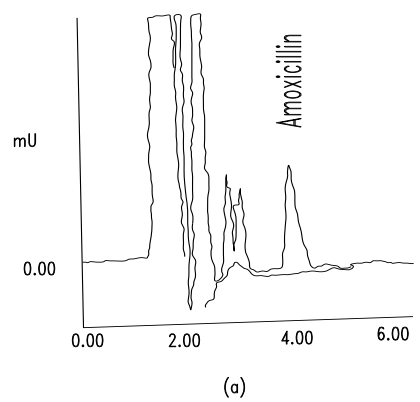

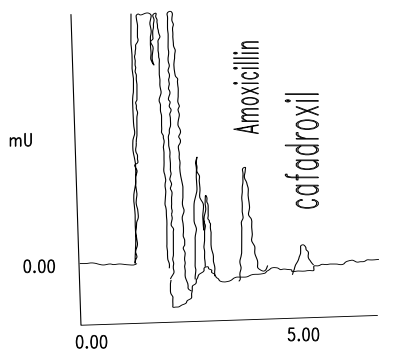

(b)

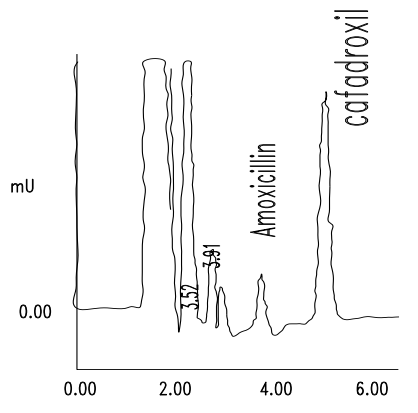

(c)

Figure 2a: typical chromatograms of:

(a) Blank human plasma spiked with amoxicillin $(5 \mu \mathrm{g} / \mathrm{ml})$.

(b) Blank plasma spiked with amoxicillin $(5 \mu \mathrm{g} / \mathrm{ml})$ and cefadroxil $(0.05 \mu \mathrm{g} / \mathrm{ml})$.

(c) Blank plasma spiked with amoxicillin, AMO $(5 \mu \mathrm{g} / \mathrm{ml})$ and cefadroxil $(4 \mu \mathrm{g} / \mathrm{ml})$.

The chromatograms of plasma sample taken (a) before administration of cefadroxil, (b) $0.25 \mathrm{~h}$, (c) $1.75 \mathrm{~h}$ and (d) $8 \mathrm{~h}$ after oral administration of ULTRACEF ${ }^{\circledR} 500$ Capsules (containing $500 \mathrm{mg}$ ) to a human volunteer are shown in figure $\mathbf{2 b}$. 


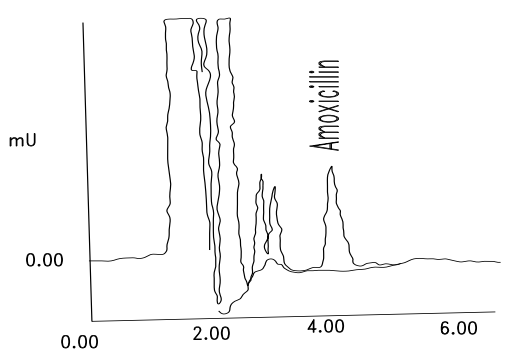

(a)

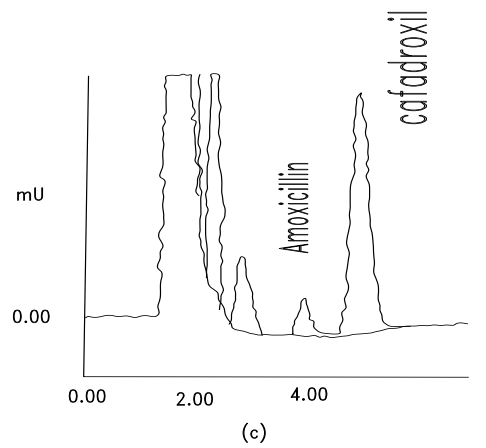

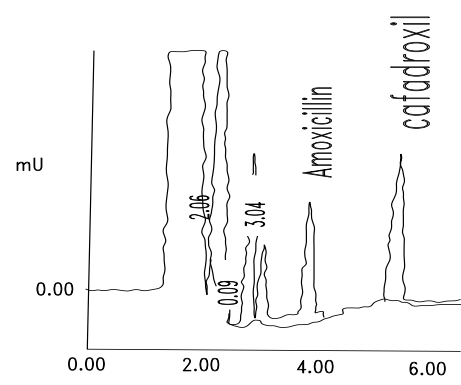

(b)

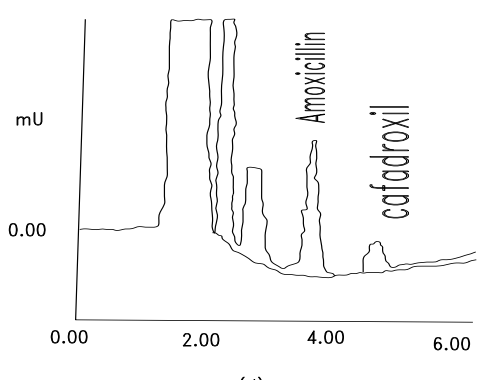

(d)

Figure 2 b: Typical Chromatograms of human plasma samples taken:

(a) Before administration of cefadroxil

(b) $0.5 \mathrm{~h}$ after administration of cefadroxil to a human volunteer.

(c) $2 \mathrm{~h}$ after administration of cefadroxil to a human volunteer.

(d) $10 \mathrm{~h}$ after administration of cefadroxil to a human volunteer.

The selectivity of the method was demonstrated by the lack of interferences at the retention times of AMO (3.8 min) and CFL (4.8 min). Both peaks were sharp and symmetrical with good baseline resolution, thus facilitating accurate measurement of the peak height ratio. Potential interferences to the peaks were also evaluated by injecting some common drugs to the HPLC system.

\section{Linearity of the calibration plots}

\section{Standard plot of diclofenac sodium in plasma}

The peak-height ratio, (PHR) of DF/MA versus the spiked concentrations of diclofenac sodium in the range of 0.01-10 $\mu \mathrm{g} / \mathrm{ml}$ gave excellent linear responses for inter-day ( Table 2-A, 2-B) and intra-day calibration plots (table 3-A, 3-B) to a power function, $\mathrm{y}=\mathrm{a} \mathrm{x}^{\mathrm{b}}$, with a weighting factor 1 (using simple computer program with iterative technique).

A typical standard plot of diclofenac sodium in plasma (Figure 3) can be described by the equation: 


$$
\text { PHR }=0.086(\text { Conc. })^{1.817}, \quad r^{2}>0.999 \quad \text { Eq.1 }
$$

By which diclofenac sodium plasma concentrations of dosed samples is given by:

$$
\text { MeasuresdConc. }=0.086 \sqrt[1]{\frac{P H R}{1.817}} \quad \text { Eq. } 2
$$

The correlation coefficient $\left(\mathrm{r}^{2}\right)$ of greater than 0.999, indicating a good fit to the least square linear regression analysis.

Table 2-a: Inter-day reproducibility ${ }^{1}$ of calibration curves of diclofenac sodium in human plasma.

\begin{tabular}{lll}
\hline Plasma Conc. $(\boldsymbol{\mu g} / \mathbf{m l})$ & Mean Peak Height Ratio $\pm \mathbf{S D}^{\mathbf{2}}$ & $\boldsymbol{\%}_{\mathbf{R S D}}(\mathbf{n}=\mathbf{4})^{\mathbf{3}}$ \\
\hline 0.01 & $0.065 \pm 0.01$ & 15.384 \\
0.05 & $0.150 \pm 0.02$ & 13.333 \\
0.1 & $0.240 \pm 0.03$ & 12.500 \\
0.5 & $1.100 \pm 0.03$ & 2.2727 \\
1 & $1.980 \pm 0.14$ & 7.0707 \\
2 & $3.650 \pm 0.17$ & 4.6575 \\
5 & $9.190 \pm 0.25$ & 2.7203 \\
10 & $18.220 \pm 0.55$ & 3.0186 \\
\hline
\end{tabular}

1. Determined from four sets of standard curves prepared on four different days over a period of two weeks.

2. $\mathrm{SD}=$ Standard deviation.

$$
\% \mathrm{RSD}=\text { standard deviation Mean } / \text { X } 100
$$

Table 2-b: Inter-day calibration data of diclofenac sodium in human plasma.

\begin{tabular}{llll}
\hline Calibration Curve $^{1}$ & Slope $^{2}$ & Intercept $^{\mathbf{3}}$ & Correlation Coefficient, $^{\mathbf{2}}$ \\
\hline 1 & 1.8137 & 0.093 & 0.999955 \\
2 & 1.799 & 0.085 & 0.999445 \\
3 & 1.832 & 0.080 & 0.999555 \\
4 & 1.825 & 0.086 & 0.999255 \\
\hline
\end{tabular}

1. Prepared over a period of two weeks.

2. Mean slope $\pm \mathrm{SD}(\% \mathrm{RSD})=1.817 \pm 0.012 \mathrm{ml} / \mu \mathrm{g}(0.660 \%)$

3. Mean Intercept \pm SD $(\%$ RSD $)=0.086 \pm 0.004(4.6511)$

Table 3-A: Intra-day reproducibility ${ }^{1}$ of calibration curves of diclofenac sodium in human plasma.

\begin{tabular}{lll}
\hline Plasma Conc. $(\boldsymbol{\mu g} / \mathbf{m l})$ & Mean Peak Height Ratio \pm SD $^{2}$ & $\boldsymbol{\%}_{\text {RSD }}(\mathbf{n}=\mathbf{4})^{\mathbf{3}}$ \\
\hline 0.01 & $0.055 \pm 0.01$ & 18.181 \\
0.05 & $0.149 \pm 0.02$ & 13.422 \\
0.1 & $0.250 \pm 0.03$ & 12.000 \\
0.5 & $1.110 \pm 0.03$ & 2.702 \\
1 & $2.199 \pm 0.08$ & 3.638 \\
\hline
\end{tabular}




\begin{tabular}{lll}
\hline 2 & $3.460 \pm 0.15$ & 4.335 \\
5 & $9.290 \pm 0.22$ & 2.368 \\
10 & $18.320 \pm 0.51$ & 2.729 \\
\hline
\end{tabular}

1. Determined from four sets of standard curves prepared on four different days over a period of two weeks.

2. $\mathrm{SD}=$ Standard deviation.

3. $\%$ RSD $=$ standard deviation $X 100$

mean

Table 3-B: Intra-day calibration data of diclofenac sodium in human plasma.

\begin{tabular}{llll}
\hline Calibration Curve $^{1}$ & Slope $^{2}$ & Intercept & Correlation Coefficient, $\mathbf{r}^{2}$ \\
\hline 1 & 1.8228 & 0.1023 & 0.99968 \\
2 & 1.8822 & 0.0991 & 0.99999 \\
3 & 1.7990 & 0.1061 & 0.99988 \\
\hline
\end{tabular}

1. Prepared over a period of two weeks.

2. Mean slope $\pm \mathrm{SD}(\% \mathrm{RSD})=1.83466 \pm 0.0349 \mathrm{ml} / \mu \mathrm{g}(1.902 \%)$

PHR (DF/MA)

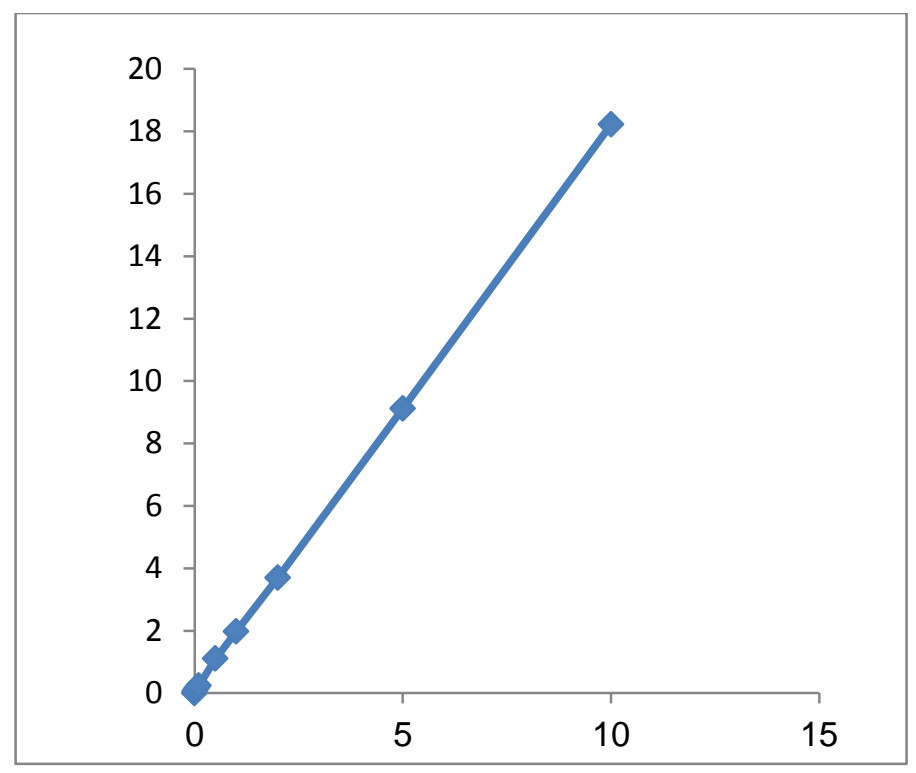

Plasma concentration of diclofenac sodium $(\mu \mathrm{g} / \mathrm{ml})$

Figure 3: Inter-day standard calibration curve of diclofenac sodium in human plasma by the proposed HPLC-UV method.

\section{Standard plot cefadroxil in plasma}

The peak-height ratio, (PHR) of CFL/AMO versus the spiked of CFL in the range of 0.05-32 $\mu \mathrm{g} / \mathrm{ml}$ gave excellent linear responses (for inter-day (Table 4-A, 4-B) and intra-day calibration plots (Table 5-A, 5-B) to a power function, $y=\mathrm{a} \mathrm{x}^{\mathrm{b}}$, with a weighting factor $=1$ (using simple computer program with iterative technique). 
A typical standard plot of cefadroxil in plasma (Figure 4) can be described by the equation:

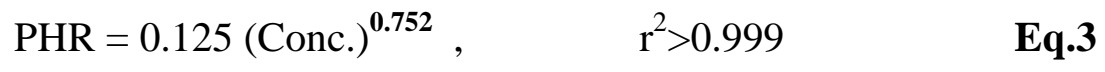

By which cefadroxil plasma concentrations of dosed samples is given by:

$$
\text { MeasuresdConc. }=0.125 \sqrt[1]{\frac{P H R}{0.752}} \quad \text { Eq. } 4
$$

The correlation coefficient $\left(\mathrm{r}^{2}\right)$ of greater than 0.999 , indicating a good fit to the least square linear regression analysis.

Table 4-A: Inter-day reproducibility ${ }^{1}$ of calibration curves of cefadroxil in human plasma.

\begin{tabular}{lll}
\hline Plasma Conc. $(\boldsymbol{\mu g} / \mathbf{m l})$ & Mean Peak Height Ratio \pm SD $^{2}$ & \% RSD $(\mathbf{n}=\mathbf{4})^{\mathbf{3}}$ \\
\hline 0.05 & $0.167 \pm 0.011$ & 6.586 \\
0.5 & $0.346 \pm 0.014$ & 4.046 \\
1 & $0.828 \pm 0.050$ & 6.038 \\
2 & $1.588 \pm 0.035$ & 2.203 \\
4 & $3.893 \pm 0.144$ & 3.698 \\
8 & $6.338 \pm 0.174$ & 2.745 \\
10 & $7.398 \pm 0.051$ & 0.689 \\
16 & $12.699 \pm 0.421$ & 3.315 \\
32 & $24.952 \pm 1.921$ & 7.698 \\
\hline
\end{tabular}

Determined from four sets of standard curves prepared on four different days over a period of two weeks.

$\mathrm{SD}=$ Standard deviation .

$$
\% \mathrm{RSD}=\text { standard deviation/ mean X } 100
$$

Table 4-B: Inter-day calibration data of cefadroxil in human plasma.

\begin{tabular}{llll}
\hline Calibration Curve $^{1}$ & Slope $^{2}$ & Intercept & Correlation Coefficient, $\mathbf{r}^{\mathbf{2}}$ \\
\hline 1 & 0.775 & 0.1279 & 0.9998 \\
2 & 0.757 & 0.1235 & 0.9974 \\
3 & 0.742 & 0.1245 & 0.9995 \\
4 & 0.735 & 0.1244 & 0.9992 \\
\hline
\end{tabular}

1. Prepared over a period of two weeks.

2. Mean slope $\pm \mathrm{SD}(\% \mathrm{RSD})=0.752 \pm 0.015 \mathrm{ml} / \mu \mathrm{g}(1.994 \%)$

3. Mean intercept $\pm \mathrm{SD}(\% \mathrm{RSD})=0.125 \pm 0.001(0.800 \%)$

Table 5-A: Intra-day reproducibility ${ }^{1}$ of calibration curves of cefadroxil in human plasma.

\begin{tabular}{lll}
\hline Plasma Conc. $(\boldsymbol{\mu g} / \mathbf{m l})$ & Mean Peak Height Ratio $\pm \mathbf{S D}^{\mathbf{2}}$ & $\boldsymbol{\%} \mathbf{R S D}(\mathbf{n}=\mathbf{3})^{\mathbf{3}}$ \\
\hline 0.05 & $0.244 \pm 0.010$ & 4.098 \\
0.5 & $0.455 \pm 0.012$ & 2.637 \\
1 & $0.888 \pm 0.011$ & 1.238 \\
2 & $1.548 \pm 0.047$ & 3.036 \\
4 & $3.248 \pm 0.026$ & 0.800 \\
\hline
\end{tabular}




\begin{tabular}{lll}
\hline 8 & $6.139 \pm 0.049$ & 0.798 \\
10 & $7.378 \pm 0.038$ & 0.515 \\
16 & $11.558 \pm 0.058$ & 0.501 \\
32 & $23.152 \pm 1.554$ & 6.712 \\
\hline
\end{tabular}

Determined from four sets of standard curves prepared on four different days over a period of two weeks.

$\mathrm{SD}=$ Standard deviation

$\%$ RSD = standard deviation/ mean X 100

Table 5-B: Intra-day calibration data of cefadroxil in human plasma.

\begin{tabular}{llll}
\hline Calibration Curve $^{1}$ & Slope $^{2}$ & Intercept & Correlation Coefficient, $\mathbf{r}^{2}$ \\
\hline 1 & 0.717 & 0.208 & 0.999 \\
2 & 0.745 & 0.247 & 0.998 \\
3 & 0.742 & 0.235 & 0.999 \\
\hline
\end{tabular}

1. Prepared over a period of two weeks.

2. Mean slope $\pm \mathrm{SD}(\% \mathrm{RSD})=0.734 \pm 0.012 \mathrm{ml} / \mu \mathrm{g}(1.634 \%)$

\section{PHR (CFL/AMO)}

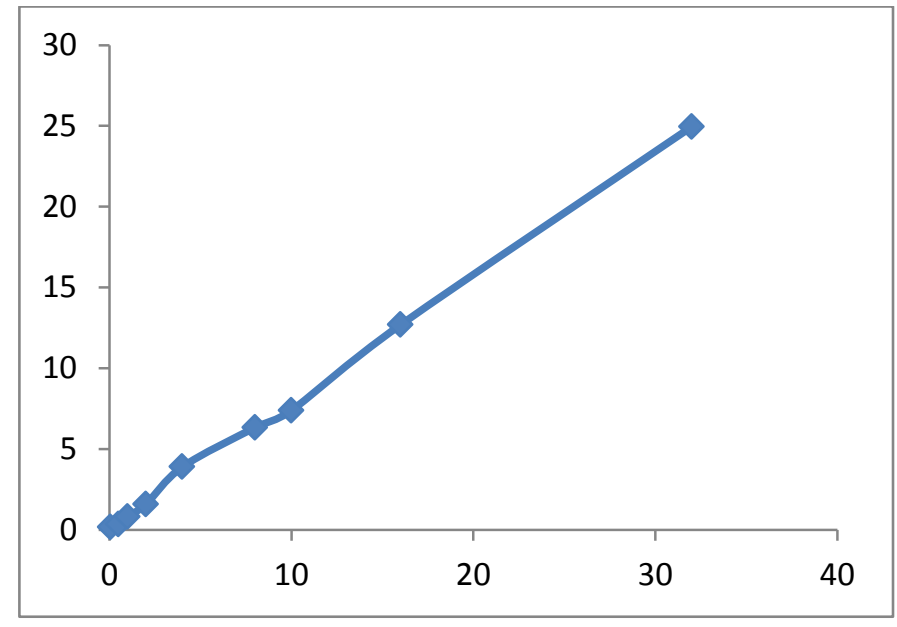

\section{Plasma concentration of cefadroxil $(\mu \mathrm{g} / \mathrm{ml})$}

Figure 4: Standard Calibration Curve For Cefadroxil In Human Plasma By HPLC-UV Method.

\section{Detection limit and reproducibility of the assay}

\section{Diclofenac sodium (DF)}

The sensitivity limit as defined by the minimum concentration of diclofenac sodium in plasma that could be detected (LLOD) with a signal to noise ratio of 4 to 1 and with statistically acceptable relative standard deviation (RSD \%) in the peak height ratio was $10 \mathrm{ng} / \mathrm{ml}$ diclofenac sodium per $\mathrm{ml}$ of plasma (Figure 3). Since this concentration of diclofenac sodium in the calibration showed acceptable relative standard deviation or RSD\% values in the inter-day 
$(15.384 \%)$ (table 2-A, 2-B) and intra-day (18.181\%) (table 3-A, 3-B) reproducibility, it was regarded as the lower limit of quantitation (LOQ) for DF in plasma.

\section{Cefadroxil (CFD)}

The minimum concentration of cefadroxil in plasma that could be detected (LOD) with a statistically acceptable RSD (\%) in the peak height ratio was $0.05 \mu \mathrm{g} / \mathrm{ml}$. Since this concentration of CFD in the calibration showed acceptable relative standard deviation or RSD\% values in the inter-day (6.586\%) (table 4-A, 4-B) and intra-day (4.098\%) (table 5-B, 5-B) reproducibility, it was regarded as the lower limit of quantitation (LOQ) for cefadroxil in plasma.

\section{Precision and reproducibility of the assay}

\section{Diclofenac sodium}

The precision of the assay was assessed by the acceptable variability in the peak height ratio at each concentration of inter-day and intra-day reproducibility of the calibration curves of diclofenac sodium in plasma (tables 2-A and 2-B, 3-A, 3-B).

The inter-day reproducibility of the assay was evaluated by comparing the linear regression analyses of four standard plots obtained from spiked human plasma samples at four different days over a period of two weeks (table 2-B). Least-squares regression analyses of the calibration curves gave linear responses over the tested concentration range of DF (0.01-10 $\mu \mathrm{g} / \mathrm{ml}$ ). The average slope of the four standard plots was $1.817 \mathrm{ml} / \mu \mathrm{g}$ with a standard deviation (SD) equal to 0.012 (table 2-B), and a day-to-day RSD (\%) of 0.660 , indicating excellent interday reproducibility. The correlation coefficient $\left(\mathrm{r}^{2}\right)$ was typically higher than 0.999 (table 2-B).

The intra-day reproducibility was determined by comparing the linear regression analyses of three standard plots obtained from spiked human plasma samples in the same day (table 3-A). Least-squares regression analyses of the three calibration curves gave linear responses in the tested concentration range of DF $(0.01-10 \mu \mathrm{g} / \mathrm{ml})$. The average slope of the three plots were $1.834 \mathrm{ml} / \mu \mathrm{g}$ with a standard deviation (SD) of 0.0349 and a RSD of $1.902 \%$, indicating good within-day reproducibility. The correlation coefficient $\left(\mathrm{r}^{2}\right)$ was also higher than 0.999 for each standard plot (table 3-B). The RSD\% values from inter-day and intra-day analysis of diclofenac sodium ranged from 2.272 to 15.384 and 2.368 to $18.181 \%$ respectively (tables $\mathbf{2}$-A and 3-A). These RSD\% values are in the acceptable range for the assay.

\section{Cefadroxil}


The precision of the assay was assessed by the acceptable variability in the peak height ratio at each concentration of inter-day and intra-day reproducibility of the calibration curves of CFD in plasma (tables 4-A and 5-A).

The inter-day reproducibility of the assay was evaluated by comparing the linear regression analyses of four standard plots obtained from spiked human plasma samples at four different days over a period of two weeks (table 4-B). Least-squares regression analyses of the calibration curves gave linear responses over the tested concentration range of CFL (0.05-32 $\mu \mathrm{g} / \mathrm{ml})$. The average slope of the four standard plots was $0.752 \mathrm{ml} / \mu \mathrm{g}$ with a standard deviation (SD) equal to 0.015, and a day-to-day RSD (\%) of 1.99 , indicating excellent inter-day reproducibility. The correlation coefficient $\left(r^{2}\right)$ was typically higher than 0.999 (table 4-B).

The intra-day reproducibility was determined by comparing the linear regression analyses of three standard plots obtained from spiked human plasma samples in the same day (table 5-A). Least-squares regression analyses of the three calibration curves gave linear responses in the tested concentration range of CFD $(0.05-32 \mu \mathrm{g} / \mathrm{ml})$. The average slope of the three plots were $0.734 \mathrm{ml} / \mu \mathrm{g}$ with a standard deviation (SD) of 0.015 and a RSD of $1.63 \%$, indicating good within-day reproducibility. The correlation coefficient $\left(\mathrm{r}^{2}\right)$ was also higher than 0.999 for each standard plot (table 5-B).

The RSD\% values from inter-day and intra-day analysis ranged from 0.689 to 7.698 and 0.501 to $6.712 \%$ respectively. These RSD\% values are in the acceptable range for the assay.

\section{Diclofenac sodium assay validation}

The present study describes a highly sensitive, accurate, and reproducible HPLC method for the determination of DF in human plasma. This method has several advantages over the previously reported methods [41-57]. Most of the published methods do not include an internal standard (IS), which is crucial because the sample preparation methods involve more than one extraction step [41-57]. Sample preparation is simpler, the chromatographic column and internal standard used are available commercially. The procedure for sample preparation is rapid and inexpensive. Because the internal standard (IS) and samples containing unknown concentrations are handled simultaneously, errors of manipulation are taken into account. The very low quantification limit of diclofenac sodium $(0.01 \mu \mathrm{g} / \mathrm{ml})(10 \mathrm{ng} / \mathrm{ml})$ (tables 2a and $2 \mathbf{B})$ obtained with a UV detector allowed us to avoid using fluorometric detection, which requires more expensive equipment. On the other hand, UV detectors give more reproducible and stable responses than fluorometric detectors [45]. Another advantage of our method was its application for the long-term stability (five months) of diclofenac sodium in frozen plasma which is essential for pharmacokinetics, 
bioavailability and bioequivalence studies. Therefore, the proposed method clearly offers advantages over the existing HPLC procedures [41-57] with respect to sensitivity, retention times, extraction times, overall recoveries and inter- and intra-day reproducibility. All the validation parameters for diclofenac sodium determination were in agreement with the criteria of the international guidelines for bio analytical method validation [63,64].

\section{Cefadroxil assay validation}

The procedure presented for determination of cefadroxil is more simple, as it doesn't include evaporation of the organic (extraction) solvent which is time consuming in many reported methods [57-59]. Also, the method doesn't include reconstitution step which is almost tedious and needs filtration step which erroneous and time consuming [57-59]. Our method is more sensitive compared to the recently published HPLC-UV method by Kano et al. 2012 [58]. The lowest limit of quantification (LLOQ) in our method is $0.05 \mu \mathrm{g} / \mathrm{ml}$ (tables 1and 2) compared to $0.4 \mu \mathrm{g} / \mathrm{ml}$ for Kano et al. 2012 [58], indicating that our method is almost ten-times more sensitive. Our method is also more faster compared to most reported methods where the retention times for cefadroxil and amoxicillin (internal standard) were 3.8 and 4.8 min., respectively (figure 2), an advantage that allow determination up to ten samples in one hour. The use of organic solvents in the extraction procedure in this work was also minimized per sample. Only two previously reported methods used flow rate in the chromatographic system equal or less than $1 \mathrm{~mL} / \mathrm{min}$. Barbhaiya [60] described a method with a flow rate of $1 \mathrm{~mL} / \mathrm{min}$, but retention time of cefadroxil was greater than $5 \mathrm{~min}$. Piotrovskij and colleagues [62] presented a method with a flow rate of $0.6 \mathrm{~mL} / \mathrm{min}$, but the retention time of cefadroxil was $13.4 \mathrm{~min}$. Despite the use of a normal flow rate of $1.5 \mathrm{~mL} / \mathrm{min}$ in the present method, shorter retention times for the cefadroxil (3.8 $\mathrm{min}$ ) and amoxicillin (IS) (4.8 $\mathrm{min}$ ) were obtained without interference by endogenous substances in the plasma in chromatographic separation (figure 2). Under the present chromatographic conditions, the run time for each sample was $7 \mathrm{~min}$. Kano et al [58] published efficient HPLC-UV assay for cefadroxil, which is still time consuming where the sample pretreatment need evaporation at $40^{\circ} \mathrm{C}$ under a stream of nitrogen and reconstitution in $300 \mu 1$ of the mobile phase, while, in the proposed method sample pretreatment not involve evaporation of the organic solvent. Moreover, the present method described a long-term stability of cefadroxil in frozen human plasma which is of major importance for bioavailability -bioequivalence studies. Therefore, the proposed method clearly offers advantages over the existing HPLC procedures [57-61] with respect to sensitivity, retention times, extraction times, overall recoveries 
and inter- and intra-day variations. All the validation parameters for cefadroxil quantification met the criteria of the international guidelines for bio analytical method validation [63-64].

Effect of altitude $(2500 \mathrm{M})$ on the plasma concentrations and pharmacokinetics of diclofenac sodium and cefadroxil.

Plasma concentrations of diclofenac sodium and cefadroxil.

The plasma concentration-time curves of diclofenac sodium (tables 6 and figure 5) and cefadroxil are plotted in the ALT and SEA (tables 7 and figures 6).

For the two drugs, there were as significant increase in the rate of absorption rate at the ALT (altitude) group as compared to the SEA (sea level or normatic) group as indicated by $\mathrm{C}_{\max }$ and AUC (figures 5 and 6). Our findings demonstrated that hypoxia at ALT could significantly increase $(\mathbf{p}<\mathbf{0 . 0 5})$ the absorption of diclofenac sodium (tables 6 and Figures 5) and cefadroxil (tables 7 and figures 6 ).

Table 6: Mean plasma concentration of diclofenac sodium at alt and sea after oral administration of Voltaren $50^{\circledR}$ tablets to 12 volunteers.

\begin{tabular}{llll}
\hline \multicolumn{4}{l}{ Mean plasma concentrations $(\boldsymbol{\mu g} / \mathbf{m l}) \pm$ SD } \\
Time $(\mathbf{h})$ & ALT & SEA & P* \\
\hline 0.5 & $0.25 \pm 0.03$ & $0.17 \pm 0.02$ & $<0.05$ \\
1 & $2.11 \pm 0.14$ & $1.70 \pm 0.11$ & $<0.05$ \\
2 & $2.88 \pm 0.24$ & $2.10 \pm 0.21$ & $<0.05$ \\
3 & $2.15 \pm 0.22$ & $1.50 \pm 0.15$ & $<0.05$ \\
4 & $1.51 \pm 0.21$ & $1.10 \pm 0.14$ & $<0.05$ \\
8 & $0.91 \pm 0.12$ & $0.50 \pm 0.08$ & $<0.05$ \\
10 & $0.39 \pm 0.04$ & $0.31 \pm 0.06$ & $<0.05$ \\
12 & $0.31 \pm 0.03$ & $0.20 \pm 0.02$ & $<0.05$ \\
\hline P* Statistical analysis was carried out using ANOVA $(\mathbf{p}<\mathbf{0 . 0 5})$
\end{tabular}

Table 7: Mean plasma concentrations of cefadroxil at alt as compared to sea after oral administration of Ultracef $^{\circledR}$ capsules $(500 \mathrm{mg})$

\begin{tabular}{llll}
\hline \multicolumn{4}{l}{ Mean plasma concentrations \pm SD } \\
Time (h) & ALT & SEA & P* \\
\hline 0.5 & $7.90 \pm 1.10$ & $4.20 \pm 1.00$ & $<0.05$ \\
1 & $12.50 \pm 1.50$ & $7.90 \pm 0.80$ & $<0.05$ \\
2 & $11.10 \pm 1.20$ & $5.00 \pm 0.60$ & $<0.05$ \\
3 & $9.20 \pm 0.99$ & $3.50 \pm 0.50$ & $<0.05$ \\
4 & $6.50 \pm 0.90$ & $2.40 \pm 0.40$ & $<0.05$ \\
8 & $2.20 \pm 0.30$ & $0.80 \pm 0.15$ & $<0.05$ \\
10 & $1.20 \pm 0.05$ & $0.30 \pm 0.05$ & $<0.05$ \\
12 & $0.65 \pm 0.03$ & $0.14 \pm 0.02$ & $<0.05$ \\
\hline
\end{tabular}

$\mathrm{P} * \overline{\text { Statistical analysis was carried out using ANOVA }(\mathbf{p}<0.05)}$ 


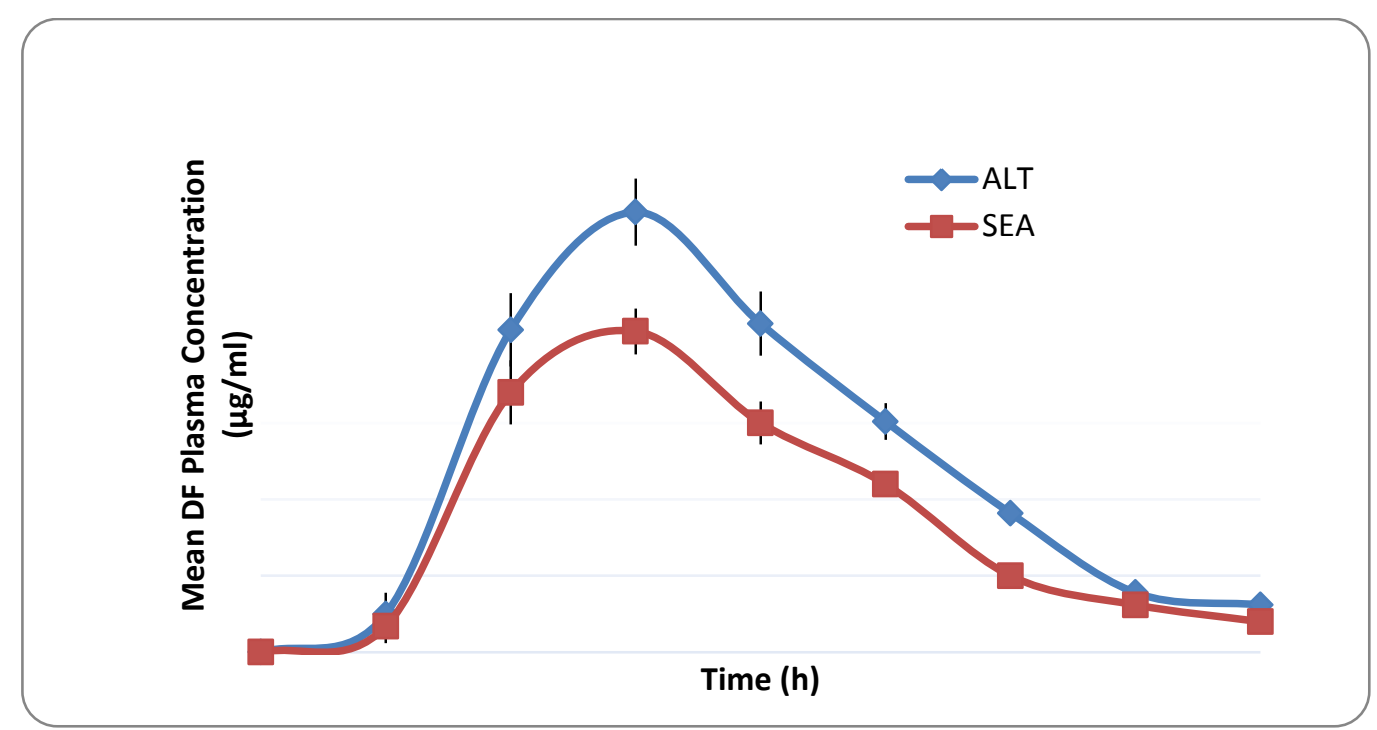

Figure 5: Mean plasma concentration of diclofenac sodium at ALT and SEA after oral administration of Voltaren $50^{\circledR}$ tablets to 12 volunteers.

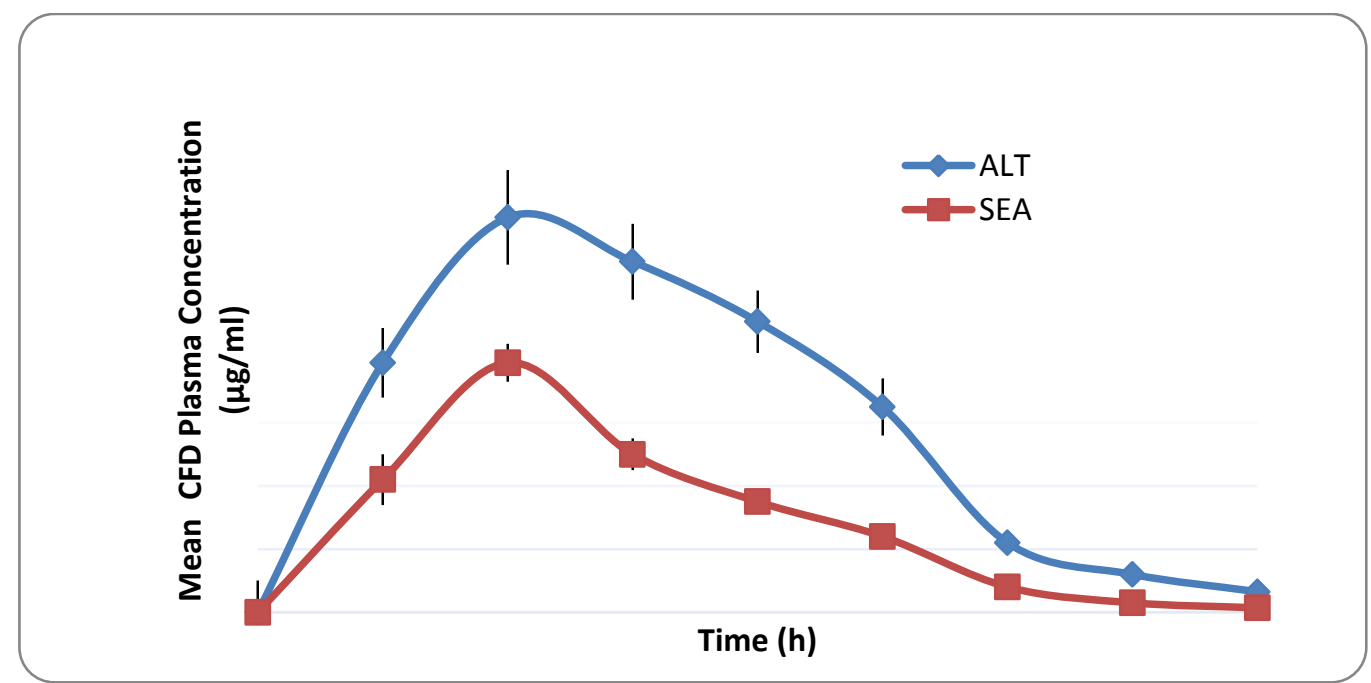

Figure 6: Mean plasma concentration of cefadroxil at ALT and SEA after oral administration of Ultracef $500^{\circledR}$ Capsules to 12 volunteers.

Pharmacokinetics parameters of diclofenac sodium and cefadroxil.

All the Pharmacokinetics parameters of both diclofenac sodium (tables 8) and cefadroxil (tables 9) at ALT (altitude) were significantly different $(\mathrm{p}<0.05)$ from SEA.

Table 8: Pharmacokinetic parameters of diclofenac sodium at ALT and SEA after oral administration of Voltaren $50^{\circledR}$ tablets to 12 volunteers.

\begin{tabular}{llll}
\hline Pharmacokinetic parameters & $\begin{array}{l}\text { Mean } \pm \text { SD } \\
\text { ALB }\end{array}$ & SEA & P* \\
\hline $\mathrm{C}_{\max }(\mu \mathrm{g} / \mathrm{ml})$ & $2.88 \pm 0.24$ & $2.10 \pm 0.21$ & $<0.05$ \\
$\mathrm{t}_{\max }(\mathrm{h})$ & $2.00 \pm 0.12$ & $2.80 \pm 0.22$ & $<0.05$ \\
$\mathrm{t}_{0.5 \mathrm{e}}(\mathrm{h})$ & $3.20 \pm 0.16$ & $2.80 \pm 0.18$ & $<0.05$ \\
\hline
\end{tabular}




\begin{tabular}{llll}
\hline $\mathrm{t}_{0.5 \mathrm{a}}(\mathrm{h})$ & $1.40 \pm 0.05$ & $1.20 \pm 0.10$ & $<0.05$ \\
$\mathrm{~K}_{\mathrm{e}}\left(\mathrm{h}^{-1}\right)$ & $0.216 \pm 0.03$ & $0.247 \pm 0.10$ & $<0.05$ \\
$\mathrm{~K}_{\mathrm{a}}\left(\mathrm{h}^{-1}\right)$ & $0.495 \pm 0.07$ & $0.577 \pm 0.10$ & $<0.05$ \\
$\mathrm{~V}_{\mathrm{d}}(\mathrm{L})$ & $21.08 \pm 1.60$ & $27.32 \pm 2.55$ & $<0.05$ \\
$\mathrm{Cl}_{\mathrm{T}}(\mathrm{L} / \mathrm{h})$ & $4.55 \pm 0.31$ & $6.74 \pm 0.78$ & $<0.05$ \\
$\mathrm{AUC}_{0-12 \mathrm{~h}}(\mu \mathrm{gh} / \mathrm{ml})$ & $13.99 \pm 2.50$ & $10.02 \pm 1.42$ & $<0.05$ \\
$\mathrm{AUC}_{0-\infty}(\mu \mathrm{gh} / \mathrm{ml})$ & $15.42 \pm 2.60$ & $10.82 \pm 2.44$ & $<0.05$ \\
\hline $\mathrm{P}^{*}$ Statistical analysis was carried out using ANOVA $(\mathbf{p}<\mathbf{0 . 0 5})$
\end{tabular}

Table 9: Pharmacokinetic parameters of cefadroxil at ALT as compared to SEA level after oral administration of Ultracef ${ }^{\circledR}$ Capsules $(500 \mathrm{mg})$.

\begin{tabular}{lllr}
\hline Pharmacokinetic parameters & $\begin{array}{l}\text { Mean } \pm \text { SD } \\
\text { ALB }\end{array}$ & SEA & P* \\
\hline $\mathrm{C}_{\max }(\mu \mathrm{g} / \mathrm{ml})$ & $20.00 \pm 2.51$ & $7.90 \pm 0.80$ & $<0.05$ \\
$\mathrm{t}_{\max }(\mathrm{h})$ & $12.50 \pm 0.11$ & $1.00 \pm 0.25$ & $<0.05$ \\
$\mathrm{t}_{0.5 \mathrm{e}}(\mathrm{h})$ & $2.60 \pm 0.25$ & $1.80 \pm 0.25$ & $<0.05$ \\
$\mathrm{t}_{0.5 \mathrm{a}}(\mathrm{h})$ & $0.60 \pm 0.11$ & $0.40 \pm 0.15$ & $<0.05$ \\
$\mathrm{~K}_{\mathrm{e}}\left(\mathrm{h}^{-1}\right)$ & $0.266 \pm 0.02$ & $0.385 \pm 0.02$ & $<0.05$ \\
$\mathrm{~K}_{\mathrm{a}}\left(\mathrm{h}^{-1}\right)$ & $1.155 \pm 0.20$ & $1.73 \pm 0.17$ & $<0.05$ \\
$\mathrm{~V}_{\mathrm{d}}(\mathrm{L})$ & $32.48 \pm 2.50$ & $582.46 \pm 4.50$ & $<0.05$ \\
$\mathrm{Cl}_{\mathrm{T}}(\mathrm{L} / \mathrm{h})$ & $8.18 \pm 1.50$ & $22.51 \pm 2.50$ & $<0.05$ \\
$\mathrm{AUC}_{0-12 \mathrm{~h}}(\mu \mathrm{gh} / \mathrm{ml})$ & $71.33 \pm 3.70$ & $28.62 \pm 4.50$ & $<0.05$ \\
$\mathrm{AUC}_{0-\infty}(\mu \mathrm{gh} / \mathrm{ml})$ & $73.77 \pm 3.97$ & $28.98 \pm 2.77$ & $<0.05$ \\
\hline $\mathrm{P}^{*}$ Statistical analysis was carried out using ANOVA $(\mathbf{p}<\mathbf{0 . 0 5})$
\end{tabular}

\section{Diclofenac sodium (DF)}

The values of the $\mathrm{C}_{\max }$ and $\mathrm{AUC}_{0-12 \mathrm{~h}}$ at $\mathrm{ALT}$ were $2.88 \pm 0.24(\mu \mathrm{g} / \mathrm{ml})$ and $13.99 \pm 2.50$ $(\mu \mathrm{gh} / \mathrm{ml})$,respectively, compared to $2.10 \pm 0.21(\mu \mathrm{g} / \mathrm{ml})$ and $10.02 \pm 1.42(\mu \mathrm{gh} / \mathrm{ml})$ for SEA, indicating significantly increase $(\mathrm{p}<0.05)$ in $\mathrm{C}_{\max }$ and $\mathrm{AUC}_{0-12 \mathrm{~h}}$ at $\mathrm{ALT}$ as compared to SEA. The apparent volume of distribution $\left(\mathrm{V}_{\mathrm{d}}\right)$ and total body clearance $\left(\mathrm{CL}_{\mathrm{T}}\right)$ were significantly lower $(\mathrm{p}<0.05)$ in the ALT group than those in the control group (SEA). The values of $\mathrm{V}_{\mathrm{d}}$ and $\mathrm{CL}_{\mathrm{T}}$ for diclofenac sodium at ALT were $21.08 \pm 1.60(\mathrm{~L})$ and $4.55 \pm 0.31(\mathrm{~L} / \mathrm{h})$, compared to $27.32 \pm 2.55$ (L) and $6.74 \pm 0.78(\mathrm{~L} / \mathrm{h})$ at SEA (tables 8).

\section{Cefadroxil (CFD)}

The values of the $\mathrm{C}_{\max }$ and $\mathrm{AUC}_{0-12 \mathrm{~h}}$ at $\mathrm{ALT}$ were $20.00 \pm 2.51(\mu \mathrm{g} / \mathrm{ml})$ and $71.33 \pm 3.70$ $(\mu \mathrm{gh} / \mathrm{ml})$,respectively, compared to $7.90 \pm 0.80(\mu \mathrm{g} / \mathrm{ml})$ and $28.62 \pm 4.50(\mu \mathrm{gh} / \mathrm{ml})$ for SEA, indicating significantly increase $(\mathrm{p}<0.05)$ in $\mathrm{C}_{\max }$ and $\mathrm{AUC}_{0-12 \mathrm{~h}}$ at ALT as compared to SEA. The $\left(\mathrm{V}_{\mathrm{d}}\right)$ and $\left(\mathrm{CL}_{\mathrm{T}}\right)$ were significantly lower $(\mathrm{p}<0.05)$ in the ALT group than those in the 
control group (SEA). The values of $\mathrm{V}_{\mathrm{d}}$ and $\mathrm{CL}_{\mathrm{T}}$ for cefadroxil at ALT were $32.48 \pm 2.50(\mathrm{~L})$ and $8.18 \pm 1.50(\mathrm{~L} / \mathrm{h})$, compared to $58.46 \pm 4.50(\mathrm{~L})$ and $22.51 \pm 2.50(\mathrm{~L} / \mathrm{h})$ at SEA (tables 9).

\section{Effect of ALT and SEA on the pharmacokinetics of diclofenac sodium and cefadroxil}

Hypoxia can cause dysfunction, damage and death to cells, tissues and organisms, and is associated with many pathophysiological processes and diseases such as stroke, asthma, emphysema, angina pectoris, myocardial infarction and tumors [1,2]. Hypoxia induced at high altitude also causes a subnormal oxygen concentration in cells which affects the drug metabolic and pharmacokinetic capacity [9]. Several studies indicate that hypoxia markedly alter the pharmacokinetic characteristics of some drugs [1,2,9-30]. Albaha area, Kingdom of saudi Arabia (KSA) is $2500 \mathrm{M}$ above sea level and is characterized by low atmospheric pressure and an increase in breathing rate. The low atmospheric pressure is well known to cause hypoxia and often alters a number of physiological parameters including changes in cardiac output, blood flow to active skeletal muscles, skin, digestive system, kidney, liver, and other organs, which consequently may alter the pharmacokinetics of a drug after administration. Therefore, any change in the pharmacokinetics due to low atmospheric pressure and oxygen deficiency will lead to a change in the therapeutic effect and duration of activity of the administered drug [1,2,9-30]. Our results showed a significant increase in the $\mathrm{C}_{\max }$ and $\mathrm{AUC}_{0-12 \mathrm{~h}}$ and decrease in the $\left(\mathrm{V}_{\mathrm{d}}\right)$ and $\mathrm{CL}_{\mathrm{T}}$, and prolongation in the elimination half-life $\left(\mathrm{t}_{0.5 \mathrm{e}}\right)$ at ALT as compared to SEA for both diclofenac sodium and cefadroxil (tables 5) could be attributed to the hypoxia at ALT. These results are in agreement with previous studies [1,2]. The protein binding rate of propranolol was significantly increased but that of metoprolol remained unchanged after acute exposure to high altitude. Compared with the rats exposed to normal altitude, the rats with acute exposure to high altitude showed significant alterations in the pharmacokinetic parameters of the drugs, shown by increased $\mathrm{C}_{\max }$ and $\mathrm{AUC}$, prolonged $\mathrm{t}_{1 / 2}$ and MRT, and lowered Clz/F of propranolol [13], and by increased $\mathrm{T}_{\max }$ and prolonged $\mathrm{t}_{1 / 2}$ and MRT of metoprolol without obvious changes of the parameters of the compartmental model. Significant changes were reported in the disposition of sulphamethoxazole in these subjects after either acute or chronic exposure to an altitude of $\sim 3780 \mathrm{~m}$ in comparison to those residing at an altitude of $\sim 400 \mathrm{~m}$ [9]. According to previous studies [1,2,9,12-33], the pharmacokinetics changes due to high altitude exposure may require dosage regimen modifications to maintain drug efficacy and safety, which should draw our attention to drug administration dosage for those planning ascent to high altitudes. 
Generally, the alterations of the in vivo metabolic process and pharmacokinetics for most of drugs in humans and animals were related with the CYP3A and some transporters $[1,13]$. But for diclofenac sodium and cefadroxil, the P-gp is not the major factor for affecting the in vivo drug exposure because diclofenac sodium and cefadroxil belongs to the first-order kinetic process in vivo transportation. Our studies indicated that the significant changes existed in the absorption, distribution, metabolism and excretion (ADME) of diclofenac sodium and cefadroxil under the ALT ( low $\mathrm{O} 2$ environment) were formed from the in vivo acute systemic hypoxia that down regulated the expression level of the selected CYP3A protein and inhibited the activity of the metabolic enzyme, resulting in alteration of the in vivo disposition and kinetics of diclofenac sodium and cefadroxil in human. Hypoxia usually alters peripheral vasoconstriction; venous return and drug enzymes, eventually leading to blood flow and drug metabolic changes. Our studies indicated that hypoxia at ALT could significantly change the pharmacokinetic characteristics of some drugs [9-18]. The present results also showed that there were an increase of $\mathrm{AUC}$ and $\mathrm{C}_{\max }$ of diclofenac sodium and cefadroxil at ALT which could be due to inhibition the activities and expression of the CYP3A1/2 proteins, suggesting that CYP3A1/2 may play a key role for pharmacokinetic change under ALT (hypoxia). Thus, even application of the treatment doses, an increased effect and toxic reaction may be appeared in hypoxic or high altitude (ALT) environment. Decreased disposition of acetaminophen in rats has been reported which was due to impaired glucuronidation and sulphation reactions [9-18]. These changes could also be induced through reduced hepatic blood flow and a lowered energy state of liver mitochondria ${ }^{40}$. Therefore, decreased blood flow in liver could also be responsible for inhibition of drug metabolism in our study. This work reports, for the first time, the data on the pharmacokinetic characteristics of diclofenac sodium and cefadroxil at Albaha, KSA high altitude (ALT). Our data provides very valuable information to guide the clinical usage in the hypoxic and high altitude medicine, as well as a better understanding of safety and efficacy of the drug.

\section{SUMMARY}

The HPLC methods described herein for both diclofenac sodium and cefadroxil are sensitive, simple, rapid, accurate, and reproducible, representing a significant improvement over many of the recently published HPLC methods for the quantitation of diclofenac sodium and cefadroxil in human plasma. The separation can be performed under the most common experimental conditions, without adding expensive special equipment. Full validation was performed to assess 
the selectivity, sensitivity, linearity, recovery, accuracy, and precision of the method. The performance criteria for the sensitivity, linearity, recovery precision and accuracy, have been assessed and were within the FDA recommended guidelines. The results presented here demonstrate that the methods are suitable for analyzing diclofenac sodium and cefadroxil in human plasma and it has been successfully applied to the pharmacokinetic characteristics of diclofenac sodium and cefadroxil at high altitude of Albaha, KSA (ALT) as compared to sea level (SEA). This work also reports, for the first time, the effect of hypoxia of Albaha, KSA high altitude, $2500 \mathrm{M}$ (ALT) on the pharmacokinetics and metabolism of diclofenac sodium and cefadroxil as compared to sea level (SEA). There was a significant increase in $\mathrm{C}_{\max }$ and AUC 0 $12 \mathrm{~h}$, of both drugs at ALT as compared to SEA. The values of $\mathrm{Vd}$ and $\mathrm{Cl}_{\mathrm{T}}$ were significantly lower at ALT than SEA. ALT could Significantly inhibit the metabolism and renal excretion of both drugs as indicated by significant increase in the elimination half-lives $\left(\mathrm{t}_{0.5 \mathrm{e}}\right)$ and decrease in the elimination rate constant $\left(\mathrm{K}_{\mathrm{e}}\right)$ and total renal clearance $\left(\mathrm{Cl}_{\mathrm{T}}\right)$ at ALT as compared to SEA. The obtained results clearly indicate that the plasma concentrations and all the pharmacokinetic parameters of both diclofenac sodium and cefadroxil are significantly modified by ALT. The pharmacokinetics changes due to high altitude exposure may require dosage regimen modifications to maintain drug efficacy and safety, which should draw our attention to drug administration dosage for those planning ascent to high altitudes[1,2, 11-18]. Therefore, dosage regiemens adjustment is important when diclofenac sodium and cefadroxil are prescribed for administration at high altitude (ALT) to avoid toxicity.

\section{CONCLUSION}

The HPLC methods described herein for both diclofenac sodium and cefadroxil are sensitive, simple, rapid, accurate, and reproducible, representing a significant improvement over many of the recently published HPLC methods for the quantitation of diclofenac sodium and cefadroxil in human plasma. The obtained results clearly indicate that the plasma concentrations and all the pharmacokinetic parameters of both diclofenac sodium and cefadroxil are significantly modified by ALT.

\section{ACKNOWLEDGEMENT}

The authors greatly appreciate financial supporting provided by the Albaha University Deanship of Scientific Research, Kingdom of Saudi Arabia, Ministry of Higher Education (Grant No. 73/1438 ) $1438 \mathrm{H}$. 


\section{REFERENCES}

1. Wenwen Gong, Pingxiang $\mathrm{Xu}$, Shanshan Guo, Xiaorong Li, Zengliang Jin, Yuming Zhao,a Ming Fanb and Ming Xue, .- Effect of intermittent hypobaric hypoxia on efficacy \& clearance of drugs. RSC Adv., 2017; 7: 25414.

2. Hui L, Rong W, Zheng-Ping J, Juan X, Hua X. Effects of High Altitude Exposure on Physiology and Pharmacokinetics, Curr Drug Metab. 2016; 17(6):559-65.

3. VijAnjana G, Kishore K, Dey J. Effect of intermittent hypobaric hypoxia on efficacy \& clearance of drugs, Indian J Med Res. February, 2012; 135(2): 211-216.

4. Costa LE. Hepatic cytochrome P-450 in rats submitted to chronic hypobaric hypoxia, Cell Physiol, 1990; 28:C654-C659.

5. Blackmon JR, Rowell LB. Hepatic splanchnic function in acutely hypoxemic humans at rest, Am J physiol. 1986; 251:R887-R892.

6. Rowell LB, Blackmon JR, Kenny M.A, Escourru P. Splanchnic vasomotor and metabolic adjustments to hypoxia and exercise in humans, Am J Physiol., 1984; 247: H251-H258.

7. Rowell LB. Cardiovascular adjustments to hypoxemia. In: Rowell LB (ed) Human circulation: regulation during physical stress. Oxford University Press, Oxford New York, 1986; pp 213-256.

8. Ramsoe K, Jarnum S, Preisig R, Tauber J, Tygstrup N, Westergard H., Liver function and blood flow at high altitudes. J Appl Physiol., 1970; 28:725-727.

9. XY LI, F Gao, Li ZQ, W Guan, WL Feng, RL Ge. Comparison of the pharmacokinetics of sulfamethoxazole in male Chinese volunteers at low altitude and acute exposure to high altitude versus subjects living chronically at high altitude: An open-label, controlled, prospective study. Clin Ther, 2009; 31:2744-54.

10. Fradette C, Du Souich P. Hypoxia-inducible factor-1 and activator protein-1 modulate the upregulation of CYP3A6 induced by hypoxia Br J Pharmacol., 2003; 140:1146-54.

11. Fradette C, Du Souich P. Effect of hypoxia on cytochrome P450 activity and expression. Curr Drug Metab. 2004; 5:257-71.

12. Jürgens G, Christensen H., Brøsen, Sonne J, Loft S, Olsen NV. Acute hypoxia and cytochrome P450-mediated hepatic drug metabolism in humans, Clin Pharmacol Ther. 2002; 71:214-20. 
13. Nan Fang Yi Ke Da Xue Xue Bao., Effect of acute exposure to high altitude on pharmacokinetics of propranolol and metoprolol in rats, J Southern Medical Univ., 2014; 34(11):1616-20.

14. Anjana G. Vij, Krishna Kishore, Joginder Dey. Effect of intermittent hypobaric hypoxia on efficacy \& clearance of drugs, Indian J Med Res. 2012; Feb; 135(2): 211-216.

15. Arancibia A, Nella Gai M, Paulos C, Chávez J, Pinilla E, Angel N, Ritschel WA. , Effects of high altitude exposure on the pharmacokinetics of furosemide in healthy volunteers, Int J Clin Pharmacol Ther. 2004; Jun, 42(6):314-20.

16. Kamimoci $C$ H, Eddhgtctr N, Lugo S, Durkot J A, Brunhart A C. Effects of altitude $(4300 \mathrm{M})$ on the pharrnacokinetics of caffeine and cardio-green in humans, Eur J Clin Phannacol. 1995; $48:$ 167-1 70.

17. Jones DP. Hypoxia and drug metabolism. Biochem Pharmacol. 1981; 30 : 1019-23.

18. Woodrooffee AJM, Bayliss MK and Park GR. The effect of hypoxia on drug metabolizing enzymes. Drug Metab Rev. 1995; 27 : 471-95.

19. Engel G, Hofmann U, Heidemann H, Cosme J,Eichelbaum M. Antipyrine as a probe for human oxidative drug metabolism: Identification of the cytochrome P450 enzymes catalyzing 4-hydroxyantipyrine, 3-hydroxymethylantipyrine, and norantipyrine formation, Clin Pharmacol Ther. 1996; 59 : 613-23.

20. Grek OR, Dolgov AV, Iziumov EG, Loktev VB. Metabolism of xenobiotics in the liver in acute hypoxia in intact mice and mice adapted to oxygen deficiency. Farmakol Toksikol. 1984; 47 : 98-101.

21. Bonkovsky HL, Lincoln B, Healey J, OU LC, Sinclair PR, Muller-Eberhard U. Hepatic heme and drug metabolism in rat with chronic mountain sickness, Am J Physiol. 1986; $251: \mathrm{G} 467-74$.

22. Perreault S, Saunier C, Ong H, Du Souich P. Influence of hypoxia and hypercapnia on the kinetics and hypokaliaemic effect of salbutamol in the rabbit, Xenobiotica. 1995; 25 : 271-81.

23. Friedman BJ, Beihn R., and Friedman JP. The effect of hypoxia on 10. thallium kinetics in cultured chick myocardial cells . J. Nucl. Med., 1987; 28 : 1453-60.

24. Yamamoto K, Tsubokawa T, Yagi T, Ishizuka S, Ohmura S, and Kobayasshi T., The influence of hypoxia and hyperoxia on the kinetics of propofol emulsion. Can J Anesth. $1999 ; 46: 1150-5$. 
25. UBC Committee on Animal Care. Euthanasia-overdose of pentobarbital. Vancouver, British Columbia, Canada: The University of British Columbia; 2005.

26. Kurdi J, Maurice H, El-Kadi AO,Ong H, Dalkara S, and. Belanger PM, et al., Effect of hypoxia alone or combined with inflammation and 3-methylcholanthrene on hepatic cytochrome P450 in conscious rabbits, Br. J. Pharmacol. 1999; 128 : 365-73.

27. Baumel I, DeFeo JJ , Lal H. Effect of acute hypoxia on 18. brain-sensitivity and metabolism in barbiturates in mice, Psychopharmacology, 1970; 17 :193-7.

28. Riepe MW, Kasischke K, Raupach A, Carpenter DO. Acetylsalicylic acid increases tolerance against hypoxic and chemical hypoxia. Stroke, 1997; $28: 2006-11$.

29. Grissom CK, Roach RC, Sarnquist FH, Hackett PH. Acetazolamide in the treatment of acute mountain sickness: clinical efficacy and effect on gas exchange. Ann Intern Med $1992 ; 116: 461-5$.

30. Broman M, Kallskog O. The effect of hypothermia on renal. function haemodynamics in the rat. Acta Physiol Scand. 1995, 153 : 179-84.

31. Boylan JW, Hong SK. Regulation of renal function in hypothermia. Am. J. Physiol. 1966; $211: 1371-8$.

32. Jones DP, AW TY, Shan X. Drug metabolism and toxicity during hypoxia, Drug Metab Rev., 1989; 20:247-260.

33. Aw TY, Shan XQ, Sillau H ,Jones DP. Effect of chronic hypoxia on acetaminophen metabolism in rat. $1991 ; 42: 1029-38$.

34. Reynolds, JEF. Martindale, The Extra Pharmacopoeia, The Royal Pharmaceutical Society, Great Britain, London. 2002, Vol. 33, pp 30-32,.

35. Furst DE , Munster T. Nonsteroidal anti-inflammatory drugs, disease modifying antirheumatic drugs, nonopioid analgesics and drugs used in gout. In: Katzung BG. Basic and clinical pharmacology, $8^{\text {th }}$ ed. New York, Mc Graw - Hill, 2001; pp 598-99, 604.

36. Ku EC, Wasvary J.M, and Cash W.D., Diclofenac sodium (GP 45840, Voltaren), a potent inhibitor of prostaglandin synthetase, Biochem. Pharmacol. 1985; 24: 641-643.

37. Menasse R, Hedwall PR, Kraetz ., Pericin C, Riesterer L, Sallmann A, Ziel R. , Jaques R. Pharmacological properties of diclofenac sodium and its metabolites, Scand. J. Rheumatol., 1978; 22: 5-16.

38. Brogen RN, Heel RC, Pakes GE, Speight TM, Avery GS. Diclofenac sodium: a review of its pharmacological properties and therapeutic use in rheumatic diseases and pain of varying origin, Drugs. 1980; 20: 24-48. 
39. Terhaag B, Gramatte T, Hrdlcka P, Richter K. , Feller K. The influence of food on the absorption of diclofenac as a pure substance. Int J Clin Pharmacol Ther. Toxicol. 1991; 29: 418-421.

40. Mohammed FA, Jun HW, EL-Faham TH, Sayed HA, Hafez E I. An improved HPLC Procedure for the Quantitation of Diclofenac in Plasma. Liquid Chromatogr. 1994; 17(5) p.1065-1088.

41. Arcelloni C, Lanzi R, Pedercini S, Molteni G, Fermo I, Pontiroli A, Paroni R. High performance liquid chromatographic determination of diclofenac in human plasma after solid-phase extraction. J Chromatogr. B. 2001; 763: 195-200.

42. Emami J., Varshosaz J., Flamarzian M. and Tahvilian R., High performance liquid chromatographic determination, pharmacokinetic and comparative bioavailability studies of cisapride, J Pharm Biomed Anal. 2003; 33: 513 - 520.

43. Avgerinos A, Karidas T, Malamataris S. Extractionles high-performance liquid chromatographic methodfor the determination of diclofenac in human plasma and urine. J Chromatogr. 1993; 619(2): 324-329.

44. El-Sayed YM, Abdel-Hameed ME, Suleiman MS, Najib NM. A rapid and sensitive highperformance liquid chromatographic method for the determination of diclofenac sodium in serum and its use in pharmacokinetic studies, J Pharm Pharmacol., 1988; 40 (10): 727-729.

45. Moncrieff J. Extractionless determination of diclofenac sodium in serum using reversedphase highperformance liquid chromatography with fluorimetric detection, J Chromatogr. 1992; 577 (1): 185- 189.

46. Hiari T, Matsumuto S, Kishi I. Simultaneous analysis of several non-steroidal antiinflammatory drugs in human urine by high-performance liquid chromatography with normal solid-phase extraction. JChromatogr B Biomed Sci Appl. 1997; 692: 375-88.

47. Millership JS, Hare LG, Farry M, Collier P., McElnay JC, Shields MD, Carson DJ. The use of hydrophilic lipophilic balance copolymer SPE cartridges for the extraction of diclofenac from small volume pediatric plasma samples. J Pharm Biomed Analysis. 2001; 25: 871-879.

48. Mason JL, Hobbs GJ. A rapid high performance liquid chromatographic assay for the measurement of diclofenac in human plasma, J Liq Chromatogr. 1995; 18: 2045-2058. 
49. Zecca L, Ferrario P, Costi P. Determination of diclofenac and its metabolites in plasma and cerebrospinal fluid by high-performance liquid chromatography with electrochemical detection. J Chromatogr. 1991; 567(2): 425-432.

50. Torres-Lopez JE, Robles MB, Perez-Urizar J. Flores-Murrieta FJ, Granados-Soto V. Determination of diclofenac in micro-whole blood samples by high-performance liquid chromatography with electrochemical detection. Application in a pharmacokinetic study, Arzneimittelforschung. 1997; 47(9): 1040-1043.

51. Blaghrough IS, Daykin MM, Doherty M, Patrick M. and Shaw PN. High performance liquid chromatographic determination of naproxen, Ibuprofen and diclofenac in plasma and synovial fluid in man. J Chromatogr. 1992; 578: 251-257.

52. Giagoudakis G, Markantonis L. An alternative high-performance liquid chromatographic method for the determination of diclofenac and flurbiprofen in plasma, $\mathrm{J}$ Pharm BiomedAnal. 1998; 17(4-5): 897-901.

53. Roskar R, Kmetec V. Liquid chromatographic determination of diclofenac in human synovial fluid. J Chromatogr B. 2003; 788: 57-64.

54. Plavsic F, Cullig j. Determination of serum diclofenac by high-performance liquid chromatography by electrochemical detection, Hum. Toxicol. 1985; 4(3): 317-322.

55. Lee HS, Kim EJ, Zee OP, Lee YJ. High performance liquid chromatographic determination of diclofenac sodium in plasma using column-switching technique for sample clean-up.Arch Pharm. 1989; 322: 801-806.

56. Lee HS, Jeong CK, Choi SJ, Kim BS, Lee MH, Ko GI, Sohn DH. Simultaneous determination of aceclofenac and diclofenac in human plasma by narrowbore HPLC using column switching. J Pharm Biomed Anal. 2000; 23: 775-781.

57. Ottom S, Hassn M, Najib N. Comparative Bioavailability of Two Cefadroxil Products Using Serum and Urine Data in Healthy Human Volunteers. Clin Exp Pharmacol Physiol. 2004; 31: 433-437.

58. Kano K, Reis-serra CHD, Koono EE.M, Fukuda K, PortaA V. An Efficient HPLC-UV Method For The Quantitative Determination of Cefadroxil in Human Plasma and its Application in Pharmacokinetic Studies, J Liq Chromatogr.\& Rel.Technol. 2012; 35:1871-1881.

59. Tanrisever B, Santella PJ. A Review of Its Antibacterial, Pharmacokinetic and Therapeutic Properties in Comparison with Cephalexin an Cephradine. Drugs, 1986; 32: $1-16$. 
60. Barbhaiya RH. A Pharmacokinetic Comparison of Cefadroxil and Cephalexin After Administration of 250, 500 and 1000mg Solution Doses, Drug Dispos. 1996; 17: 319330.

61. Eshra AG, Hassan EM, EL-walily AFMJ. HPLC Method of Analysis of Cephadroxil and Its Application in Bioavailability Studies. Clin. Pharm. Ther. , 1993; 18: 331-335.

62. Piotrovsku VK, Gajdos M, Illek B, Dzurik R, Trnovec T. Application of a Population Pharmacokinetic Modeling to Bioavailability=Bioequivalence Study of Cefadroxil Preparations, Int J Pharm. 1995; 119: 213-221.

63. Ritschel W.A.- Handbook of basic pharmacokinetics, 3rd edn. Drug Intelligence Publications. Hamilton, Illinois., 1986.

64. Welling PG. Pharmacokinetics: processes and mathematics. ACS, American Chemical Society, Washington, DC., 1986; Monograph 185.

65. Hussein MA, Mohammed FA. Synthesis and Pharmacokinetic studies of Effective and Safe New Antimicrobial Derivatives of Substitited Hydroquinoxaline-2,3-diones, Amer j Pharm.\& Health Res, 2016; ;4(11):50-72.

\section{AJPHR is}

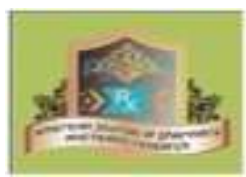

Peer-reviewed

monthly

Rapid publication

Submit your next manuscript at

editor@ajphr.com / editor.ajphr@gmail.com 